\title{
HOMES OF HOPE: VisUalizing Social ReSPONSIBILITY
}

\author{
Lauren Jatana Vathje, Marjan Eggermont, Robert Brennan \\ University of Calgary \\ lvathje@gmail.com, meggermo@ucalgary.ca, rbrennan@ucalgary.ca
}

\begin{abstract}
A sense of professional social responsibility is a key quality for engineers of the 21 st century. Community Engaged Learning (CEL) is an excellent way to develop social responsibility (SR) in students. But, there is a need to better understand how different types CEL experiences impact SR development. Recently, a psychological framework and survey has been created that addresses how SR develops in engineers. We put these SR tools to the test, along with some other measures, to see how a short-term international CEL experience impacted the students' SR development.
\end{abstract}

This study was of an exploratory nature to see how to best work with the new psychological framework and other measures of SR. All indicators showed that the short term international CEL had a positive impact on $S R$ development and the SR tools proved to be useful in interpreting and visualizing the impact on students. Our future work aims to conduct many studies like this, to see if we can understand how different types of CEL relate to development of different areas of SR in students.

Keywords: Social Responsibility, Community Engaged Learning, Service Learning, Learning Through Service

\section{INTRODUCTION}

A sense of professional global or social responsibility (SR) is a key quality for the 21 st century engineer [1], [2]. However, developing engineering programs that effectively cultivate social awareness and responsibility is difficult to ensure. The intricacies of one's sense of responsibility to society are rooted in one's values; This makes teaching and assessment of social responsibility a challenge.

It has always been important for engineers to develop a sense of SR, but it is becoming more critical as the problem solving focus of engineering work is changing away from strictly technical problems towards problem solving in a broader social and global context [1]. 21 st century engineers are increasingly responsible to solve the 'grand' challenges of society [2]. These grand challenges, as identified by the National Academy of
Engineering, will revolve around global access to clean drinking water, making solar energy economical, engineering better medicines and so on. Engineers play a critical role in solving these grand challenges because of their distinct professional ability, but it is now more important than ever to encourage and embed the development of professional social awareness and responsibility in engineering education to develop engineers that are motivated and ready to manage these grand challenges of the 21 st century.

The shift to prepare engineers of tomorrow is also apparent by the array of different graduate attributes/outcomes required by the educational accreditation boards for programs in Canada [3] and the United States [4]. SR is related to at least two attributes that an engineering student should possess at the end of their education- "understanding the impact of engineering on society and the environment" and "professionalism" (and the equivalent American outcomes [5]). Professionalism highlights the engineering role in society and emphasizes the first and foremost responsibility to the public [3]. These are 2 out of the 12 Canadian accreditation attributes, and similarly 2 out of the 11 American accreditation outcomes. Two attributes make up $33 \%$ (or 2 out of 6 ) of the professional skills, which are considered to be more difficult to teach and assess in traditional engineering programs in comparison with technical counterparts [6]. The accreditation boards' emphasis on development of these attributes underlines the necessity to develop a way to teach and assess social responsibility and the related attributes.

Community Engaged Learning (CEL) has been established in many engineering programs. CEL experiences can reach to a diverse array of outcomes, like increased possibility of pursuing a career that involves service increased awareness and empathy development [7],[8],[9]. Forming one's personal values and beliefs is also something that is done best through experiences and reflections. CEL is a perfect fit for this due to its project based/experiential nature. In recent years, the incorporation of CEL activities in engineering programs has been gaining a lot of momentum [9]. There are also many successful examples of CEL (or Learning Through Service) programs, such as EPICS at Purdue, SLICE at the University of Massachusetts, and a new one at 
Memorial called Yaffle, that developed a database of projects that link students to learning opportunities in the community. However, not all community engagement experiences are equal. There are different factors to choosing a community-engaged learning experience [10] or ways to label them [11] and it is still unclear how different CEL experiences impact students development of SR [12]. If we can understand how different types of community-engaged learning develop social responsibility in different students, then engineering programs or large community engaged platforms like EPICS could strategically incorporate different types of CEL experiences into their programs, to develop engineers with a well-established sense of professional social responsibility.

Recently, an assessment tool (EPRA) and a psychological model (PSRDM) [5] were developed to help understand how different learning experiences impact student's development of SR. Now that extensive work has gone into the development of an engineeringspecific survey tool and psychological model, we can begin the next step: to leverage these tools to understand how different types of CELs develop different aspects of SR.

As illustrated in Figure 1, in the long term, we wish to explore the question of how each different type of CEL experience can develop different constructs or realms of SR. In other studies measuring SR in engineers, SR development depends not only on the features of the CEL experience, but may develop differently depending on demographic traits, motivations, initial state of SR and predispositions among other factors [12].

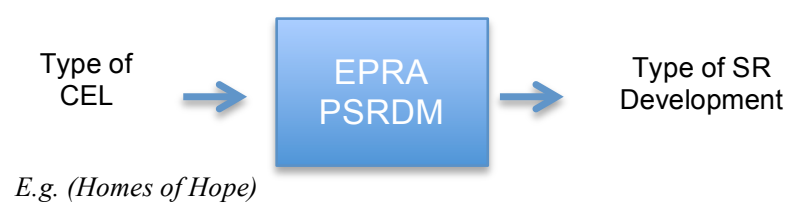

Fig. 1. Overview of Purpose of Study

The purpose of this study was exploratory in nature, to explore the measurement of SR and impact of a CEL experience with the new PSRDM/EPRA tools. We started with a short-term, service CEL experience called Homes of Hope [13]. Due to the small sample size, the actual impact on SR activity or growth was only a secondary goal.

The questions we aimed to explore were:

1) Can the PSRDM/EPRA tools help us characterize the state of social responsibility of individuals and the group of participants?
2) How does a short term CEL impact students':

a. Sense of social responsibility

b. Self-efficacy in the 2 graduate attributes related to SR

c. Relation between engineering and the social dimension

This study addressed how the PDSRM model and the EPRA assessment tool enhanced understanding the development of social responsibility. The data was collected using mixed methods design. The study involved collecting quantitative data with the EPRA assessment tool to characterize the SR profiles, and additional quantitative data to measure the impact of the trip on self-efficacy with related graduate attributes. Further details regarding the impact of the Homes of Hope experience on SR development were assessed from qualitative data that was then mapped to the psychological constructs of the PDSRM model. Finally, qualitative data was assessed to also explore the impact on how students connected engineering with the service nature of the trip.

\section{BACKGROUND}

\subsection{The Homes of Hope Trip}

Every semester at the Schulich School of Engineering, a large number of engineering students from various engineering disciplines and academic years eagerly apply to participate on this service (or CEL) trip to Mexico during spring break. In Winter 2015, 32 students were randomly selected from a group of applicants to participate with the Homes of Hope trip, where students build homes for Mexican families in need. Groups were split into two teams, built two different houses, all in two days. Data on self-efficacy and SR development was collected during this Winter 2015 trip.

The type of this CEL for this trip is considered to be a short term, mostly service based (as opposed to servicelearning), CEL experience called Homes of Hope. Though the service aspect of this trip is only 2 days long, we were interested in how students related this experience to engineering and to their sense of social responsibility (SR). One of the first steps of understanding the impact on SR is being able to differentiate between CEL courses. Currently, there are a few initiatives to classify types of CEL experiences. For now, this Homes of Hope trip could be designated as an immersive [9], development type [11] and some of the course spectra [10] features are considered to be short-term, international, cocurricular, and service-oriented. 
The purpose of the trip is to build a home for a family who currently work, own a small plot of land, but have no way to take out a mortgage or loan to build a house. Ordinarily, families in this situation live in little shacks created from scrap pieces of metal, wood, or garbage. Without the chance to borrow money from the bank for a house, they can only obtain a house, quite literally, one brick (or one piece) at a time. They have rarely any electricity or running water. Families can apply to the Homes of Hope program and upon approval - volunteers from different organizations come together to build a house for the family.

The family is as much a part of the build, working side by side with the volunteers. A concrete foundation is poured, volunteers build the frames, put up interior and exterior walls, roof the house with shingles, paint the interior and exterior and provide furnishings, food and other living materials. Wiring is included in the house design, but no water lines because there is no infrastructure for residential electrical hook up or water facilities. The entire 2 days are a whirlwind of physical work, contrasted often with emotional and humbling experiences.

\subsection{Social Responsibility Conceptual Framework (PSRDM) and Assessment Tool (EPRA)}

The development of social responsibility (SR), specifically in a professional capacity, is difficult to measure [5], [10]. In 2013, Canney's doctoral thesis [14] presented a conceptual model of the psychological framework associated with the development of SR. It is called the Professional Social Responsibility Development Model, or PSRDM for short. In line with the PSRDM framework, a survey was also developed and validated as a tool to measure SR development. The survey is called the Engineering Professional Responsibility Assessment, or EPRA for short.

The PSRDM model was built from the foundation of existing psychological models [5] and combined to create a model of constructs relevant to an engineering-specific context. The model is unique in that it represents the whole SR development continuum from a completely unaware individual, to someone who embeds social obligation into all aspects of their life, including their engineering career path [5]. Note that our figure has not included the deeper constructs in the original connected realm, since the results presented in this paper do not reach that degree of $\mathrm{SR}$.

As seen in Figure 2, the model shows that there are initially two independent streams of SR development, which we refer to as the personal realm and a professional realm. Up until a certain threshold, the personal and professional streams of SR are completely independent of each other. Also note that the constructs in each realm are non-necessarily developed linearly [17].
Once SR is developed in a professional and personal capacity to a certain threshold, a critical point is reached. This is where both a sense of professional and personal obligation to society becomes connected. After this point, a third realm is reached, which we call the connected realm, and a connected sense of SR continues to strengthen in a cyclical fashion (as opposed to linearly) [14].

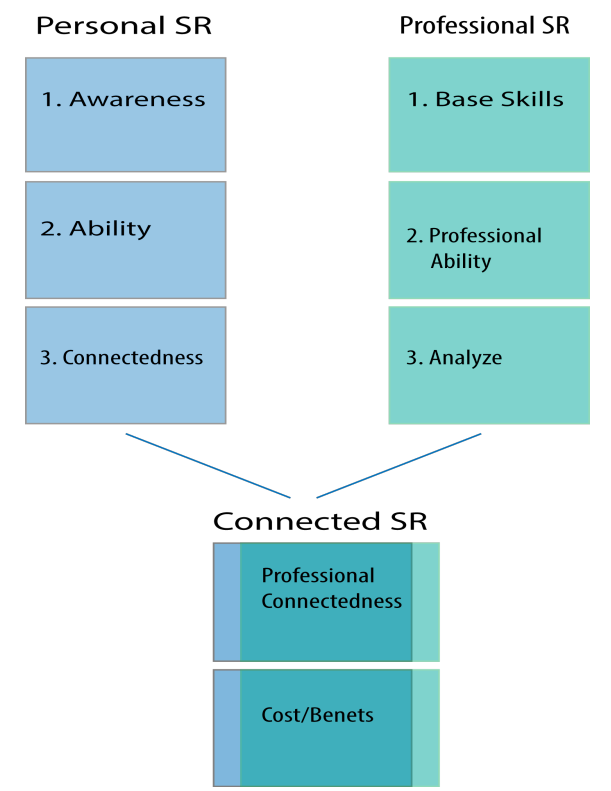

Fig. 2. PSRDM Conceptual Framework (graphic was adapted from Canney [14])

Each of the three realms of SR development are broken into individual constructs. On the personal side, it starts with "awareness", which is a recognition that others are in need. The next construct moves up to "ability", which is recognition that one can actually do something to help those in need, etc. For a list of the descriptions associated with each construct from Canney's work - see the Appendix.

To accompany the PSRDM conceptual framework, an assessment tool for measurement of SR was also developed by Canney [14] called the Engineering Professional Responsibility Assessment (ERPA) tool. This tool measures each construct in the PSRDM using a likert scale of 1-7. A sample excerpt from the EPRA assessment survey can be also seen in Appendix A.

\section{METHODOLOGY}

The survey was administered in pre-post manner. Information was collected by means of a questionnaire containing both quantitative and qualitative items, conducted and assessed in a mixed methods design. All data was derived from the pre/post survey results. 


\subsection{Survey Design}

The quantitative part of the survey consisted of the EPRA assessment tool that has a large number of questions ranked on a 7-point likert scale and directly scores students social responsibility profile in terms of the constructs/elements of the PSRDM framework model. The EPRA tool was not used to measure impact of the experience, but it helped us characterize the SR profile of individual students and the whole group of students before the experience. In addition, we also added a selfefficacy measurement developed by Brennan and Hugo [15] for each of the 12 graduate attributes, but we measured the impact on 2 attributes related to SR: "understanding the impact of engineering on society and the environment" and "professionalism". The elements of this tool provided a snapshot of how student's selfefficacy was impacted by this experience in parallel with the other measures of impact.

The qualitative part of the survey consisted of two questions. The first question asked students how they thought the trip would benefit them (in any aspect of their life). The answer to this question was coded a priori using the PSRDM model, both before and after the experience to show how students' SR was impacted. It also helped us gain a visual on the nature of the SR development in students. The second question was similar, but zoomed in on how students felt this trip would impact their capacity as an engineer. The answers to this were also coded a priori before and after the experience and mapped as either relating their perceived engineering growth with through this service experience as either technical skills growth, professional skills growth or growth in the social dimension.

Table1:

\begin{tabular}{|l|cc|}
\hline Data Type & Survey Elements \\
\hline $\begin{array}{l}\text { Quantitative } \\
\text { (See Appendix for } \\
\text { sample) }\end{array}$ & $\bullet$ & $\begin{array}{l}\text { EPRA Assessment Tool } \\
\text { (pre only) }\end{array}$ \\
\hline Qualitative & $\bullet$ & Self Efficacy Tool \\
& & $\begin{array}{l}\text { How do you think that having } \\
\text { participated on this trip will } \\
\text { benefit you in the future? } \\
\text { (Personally, Professionally, } \\
\\
\end{array}$ \\
& $\begin{array}{l}\text { Academically) } \\
\text { How do you think being apart of } \\
\text { this trip will help you become a } \\
\text { better engineer? }\end{array}$ \\
\hline
\end{tabular}

Sample of the EPRA survey, Self-efficacy questions and qualitative coding can be found in the Appendix.

The students were from the University of Calgary's Schulich School of Engineering, where enrollment total is 3039 students [16]. 32 students were accepted to attend the Winter 2015 Homes of Hope trip, of those 32 - surveys, 30 were returned back, and 26 full sets of pre/post data were used in the study analysis. Surveys that were incomplete or did not have both a pre survey and a post survey were not used in the data. The remaining 26 surveys were used in the study from all demographics.

The total participation rate was $81 \%(\mathrm{~N}=26)$. Of the 26 respondents, $46 \%(\mathrm{~N}=12)$ were female and $54 \%$ $(\mathrm{N}=14)$ were male. This sample over represented females at the Schulich School of Engineering, which has 26\% and $74 \%$ full time female, male enrollment for the 2014/2015 academic year [16]. First year students were under represented in the data at only $4 \%(\mathrm{~N}=1)$ with actual enrollment as $27 \%$. Where, third and fourth years were over represented at $42 \%(\mathrm{~N}=11), 35 \%(\mathrm{~N}=9)$, with actual population being $20 \%$ and $19 \%$ respectively. Second year students were closely represented at $19 \%$ $(\mathrm{N}=5)$, where actual enrollment shows $21 \%$. An exact breakdown on discipline was not done, but there were no students from the electrical engineering or geomatics engineering disciplines on the trip. The group was composed of civil, chemical, mechanical, oil and gas and software students.

\subsection{Analysis}

Data was analyzed using different mixed methods. The quantitative measures of SR form the EPRA tool were converted to visual graphic, which is described in a qualitative nature. To measure the impact of the experience, parallel mixed methods were used.

\subsection{Validity and Limitations}

The EPRA assessment was tool has been validated in Canney's [14] work. Due to low sample size, the impact of the service trip cannot properly represent the population. To further validate these SR trends and results, the survey gather information over multiple Homes of Hope experiences at the University of Calgary.

\section{RESULTS AND DISCUSSIONS}

\subsection{Before the Trip - Characterizing individual SR profiles and the SR landscape of the group}

By use of the Engineering Professional Responsibility Assessment (EPRA) and the corresponding PSRDM model, we were literally able to get a snapshot of the current state of Social Responsibility (SR) at the Schulich School of Engineering. As seen in Figures 3 and 4, we were able to visually characterize both individual SR profile and the overall state SR of the group. 


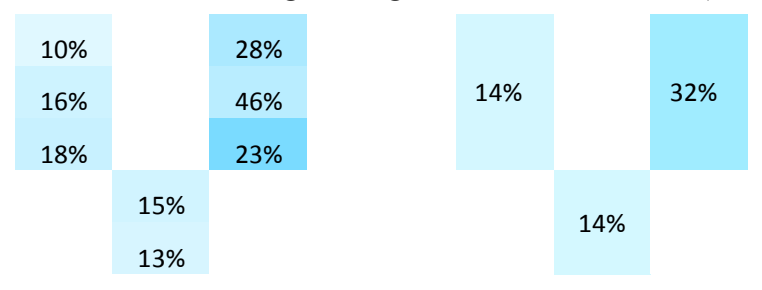

Fig. 3. Visual representation of a student's SR profile. The likert average score for each construct was calculated and used to change the saturation percent for the background of each cell.

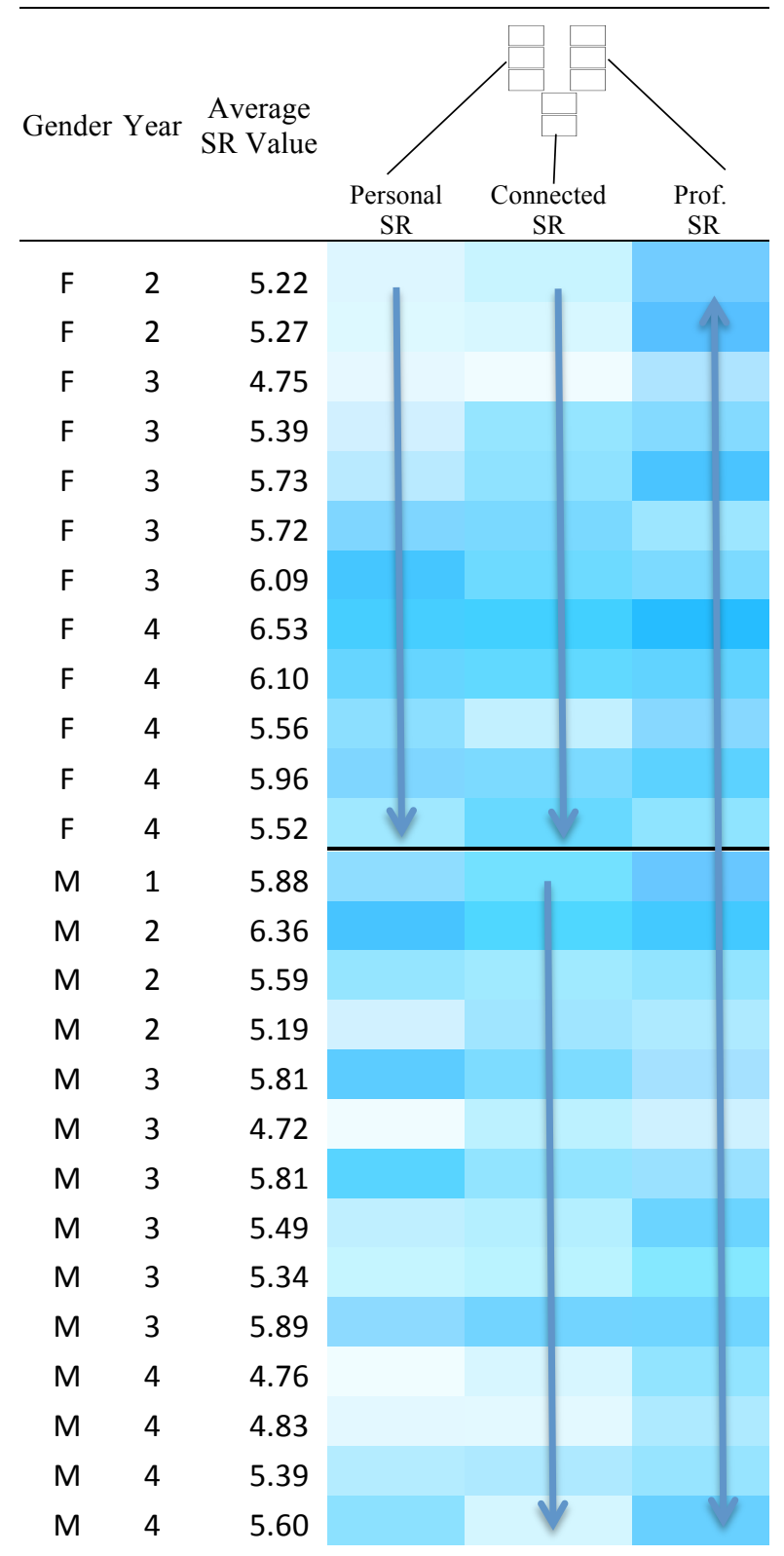

Fig. 4. Visual characterization of the SR landscape in each realm (prior to the trip) by gender and academic year.
The average SR value in each of the realms for students ranged from 4.72 to 6.53 . Thus a colour scale was developed with $0 \%$ colour saturation for $\mathrm{SR}=3.5$, and $100 \%$ saturation for $\mathrm{SR}=7$. Each construct was scored for each student and converted to a percent. One of the students SR profiles can be seen in Figure 3. The individual representations of SR were combined to create the mosaic of group SR seen in Figure 4.

By converting the EPRA results to visual representations, trends can be recognized in the group as a whole. At the individual student level, the realms of SR and each specific construct that require development can be identified.

Trend 1: Increasing personal social responsibility in women as the academic year increases in the program

Trend 2: Decreasing connected social responsibility in male students. As the academic year of student increases, the sense of social responsibility is decreasing.

Trend 3: In comparing professional ability for most engineering students (third column), there appears to be no trend - except a general higher degree of SR developing in the professional SR realm in comparison to the other realms of SR.

The tool has helped us gather a visual sense of the state of SR at our institution and at the individual level. This tool has potential to be used on a larger scale to give not only professors a sense of where their class needs SR development, but has implications at the program development level to assess different SR needs for each program.

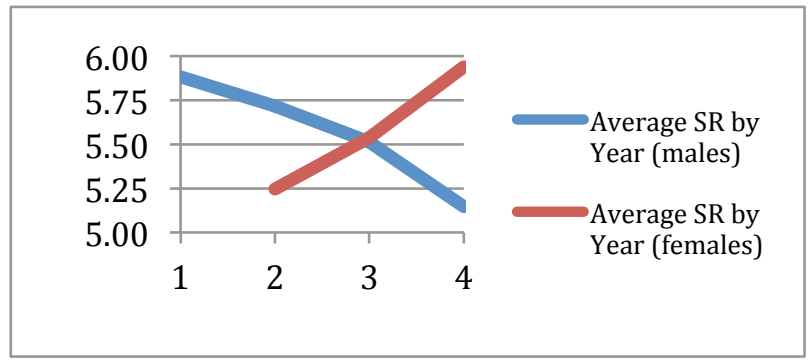

Fig. 5. Quantitative representation of the SR landscape. Confirms the same trends seen in the visual characterization of Figure 4.

To confirm the visual trends, we averaged the overall SR score for each academic year by gender and created a secondary quantitative chart. The same overall trend is confirmed in Figure 5 and Figure 4. 


\subsection{Impact of Trip - Impact on Social Responsibility}

A landscape of social responsibility (SR) was established prior to the trip. However, after a two-day experience, it would not be accurate to reevaluate the SR landscape. So, we wanted a way to map how that students connected the perceived benefits of the Homes of Hope trip to SR activity and the social dimension. To do this we asked:

"How do you think the experience of participating on the Homes of Hope trip will benefit you in the future? (Personally, Professionally, Academically)"

We then coded the responses to the constructs of the PSRDM model before and after the trip, and connected the lines. Many of the students' answers before and after the trip seemed to grow with an increased depth of relation to society. Prior to the trip students' answers revolved around expecting to meet new people, practice teamwork, gain exposure to a new culture and there were many mentions of anticipating an increase in awareness or gaining new perspective. Afterward, the length and depth of responses had increased to include perceived benefits related to awareness, humility, an increased sense of wanting to help more and appreciation. Some were quite in depth, with explicit relations between their future engineering career paths. Sample responses and coding can be seen in the Appendix. The PSRDM conceptual model of Social Responsibility development provided efficient ways to code and organize the qualitative data, in addition to providing a way to see meaningful trends in SR activity for assessment of such a short term community engaged learning experience.

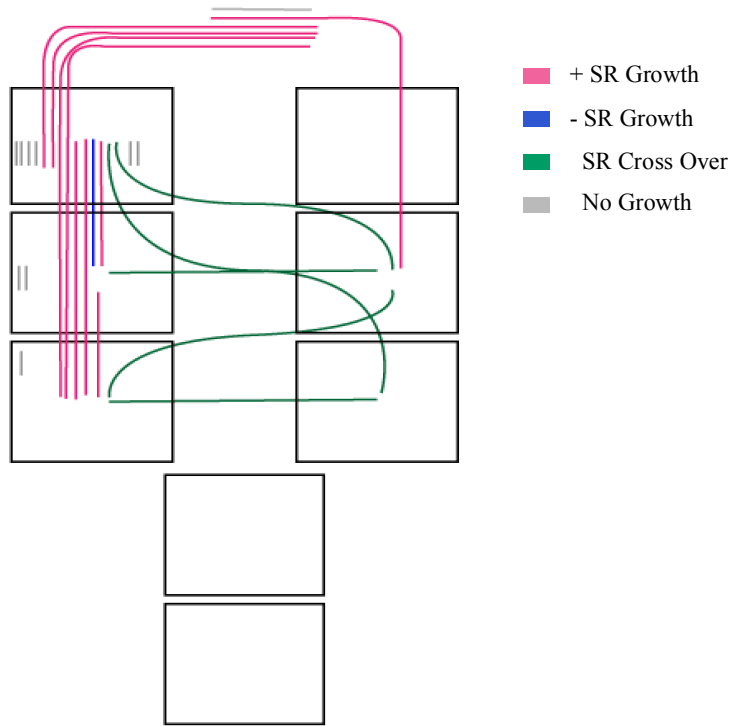

Fig. 6. Qualitative coding of pre-post SR activity on the PSRDM conceptual model
Visually in Figure 6, we can see how the majority of movements occur in the personal realm of SR. This could indicate that the Homes of Hope type of CEL experiences (co-curricular with a heavy focus on service) may develop the personal realm of SR better than other types of CEL experiences. Additionally, many of the growth patterns suggest a 'positive' growth of the connection between this trip and the social dimension.

In Figure 7 we can see a breakdown of different SR activity patterns between females and males. The first that can be noted is that prior to the experience, males typically perceived this trip with little or no benefits related to their personal growth in the social dimension, where females tended to perceive that this trip would help them enhance their sense of awareness of social needs. This may suggest that females are better at anticipating the growth they expect to experience, or it may suggest that women begin with a stronger view that social awareness growth will benefit them in the future.

Although the constructs of the PSRDM model are not necessarily linear, they are related to each other [14]. We found that on average, male students had an increase of 1 construct of social responsibility development (e.g. from 0 to awareness, or ability to connectedness), but on average female students only had an average increase in SR development of 0.16. Also note that one female student appeared to decrease in their awareness level of this experience. Despite a lower average in SR development for women, there was a higher amount of instances where women crossed over between SR in the personal realm to/from SR in the professional realm before and after the experience. This helps us characterize the way a certain CEL experience can impact different
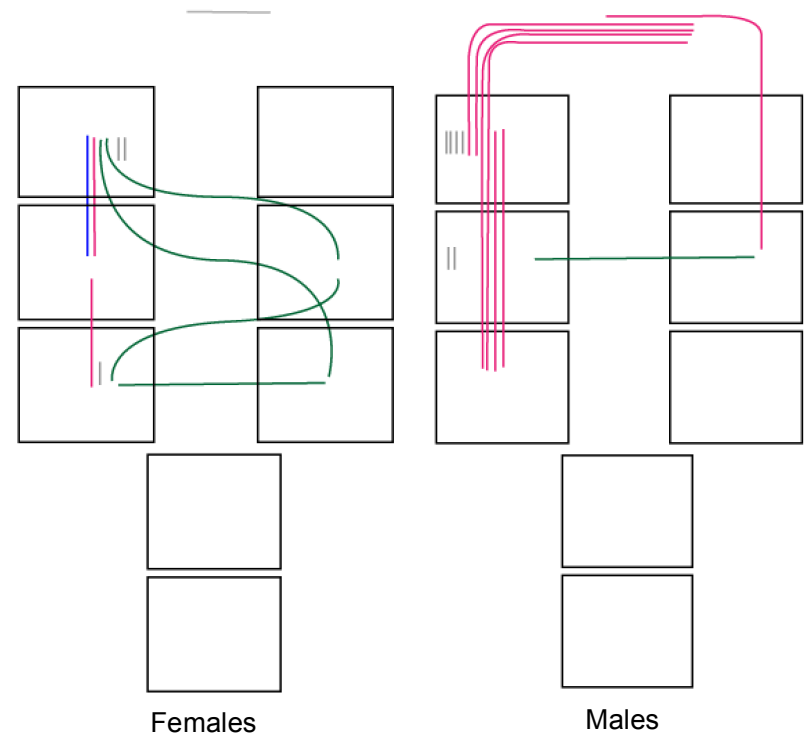

Fig 7. Break down by gender of qualitative coding of prepost SR activity on PSRDM conceptual model. 
groups in different manners. Although we have assumed that the SR growth pattern differed due to gender, it may be that the SR growth pattern differed instead to initial degree of perceived benefit, since on average, females started with a higher connection with SR prior to the trip.

\subsection{Other Indicators: Self-Efficacy Attributes and Engineering Link to the Social Dimension}

Self-efficacy in relation to 2 graduate attributes were measured both before and after the trip. There were 3 questions that corresponded to each attribute $\mathrm{s}$ that asked students to rank a percentage of how confident the student is in their ability to.... The sum was averaged for each individual attribute and averaged again for the pre and the post survey. This was done in order to get a sense of how overall self-efficacy was impacted by this experience.

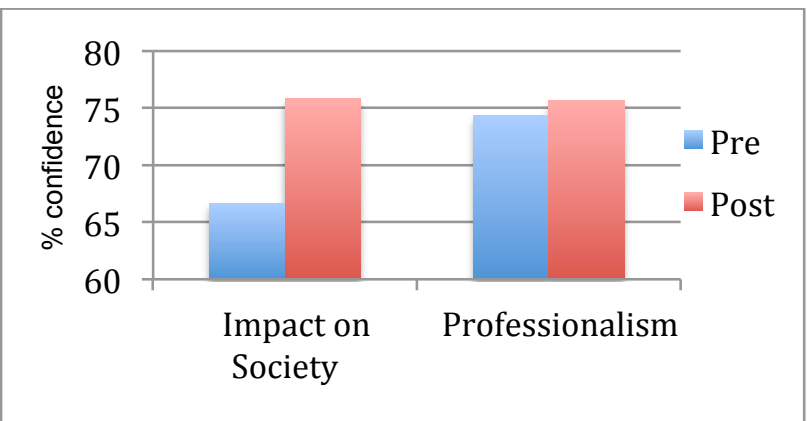

Fig. 8. Pre-post averaged scores of self-efficacy of grad attributes that are related to development of social awareness.

When looking at pre-post development of self-efficacy on the two measured graduate attributes - on average, there seemed to be a significant improvement on the attribute related to understanding the impact of engineering work on society and the environment. This implies that despite the fact that the trip was only a twoday service experience, students' confidence has increased in their perception in ability to understanding how aspects of engineering works impact society and the environment. However, professionalism was only slightly increased.

The trip had no explicit or even implied connection with engineering. Any connection that students made to engineering was completely organic. The purpose of this survey question is to understand what realm students perceive a service experience in relation to engineering career benefits, and how their perceptions change after the trip.

The survey question asked:
"What part(s) of the Homes of Hope experience do you think will help you become a better engineer?"

The trip seemed to enhance the relation between engineering and the social dimension of engineering. Responses were coded as either relating the trip to technical skills growth, professional skills growth or growth in the social dimension. This way, we could see the manner in which students related this trip to their future career path. The pre survey responses largely related this experience to impacting their engineering career with two particular skills - teamwork and meeting new people. This was represented in the professional skills dimension of the scale. Examples of responses coded to technical skills were: understanding the construction process, project management skills and working with hands. Finally, any mention of personal development in terms of becoming aware of societal needs and beyond were coded as students relating engineering profession to the social dimension. These responses mentioned things like understanding different cultures, being "aware of different societal needs", feeling like the new perspective will make them a more socially conscious engineer.

In Figure 7, the inner triangle represents the range of pre trip responses. If a student response could be related to more than one area - it was counted in both. The responses of the post survey become longer and were written in more depth, Similar to the first qualitative question. Thus before the trip, most students had one code for their initial response, or related the trip to one dimension in engineering. Afterward, students often expanded their connection between the trip to additional dimensions. The bigger triangle only shows the areas where students added a new dimension to their response so if a student's response was coded professional dimension before the trip, and afterward was professional and social, there would be only growth in the social dimension and that growth is what is shown with the bigger triangle.

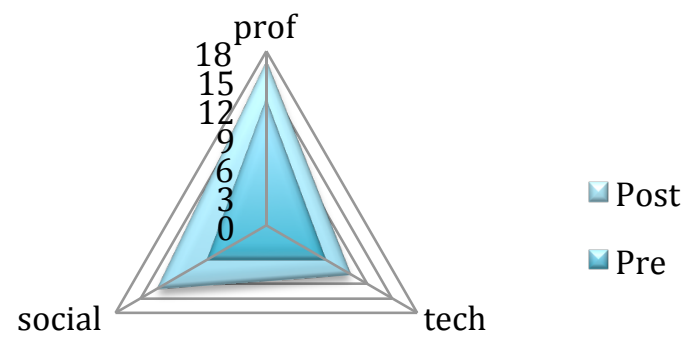

Fig. 7. The inner triangle shows how students related the experience to this trip before the trip. The bigger triangle shows in what dimensions the students expanded the relationship between engineering and service work. 


\section{CONCLUSIONS}

\subsection{Overall Conclusions}

The main purpose of our study was of an exploratory nature to see how a short-term, international community engaged learning (CEL) experience impacted the development of SR in students through use of the PSRDM model and EPRA assessment tool. Although the sample size was small, the tools were extremely useful to visually get a sense of the landscape of SR of the participants, in addition to providing a meaningful way to map qualitative information regarding the impact of the experience. Despite being only a two-day service experience, all the indicators (SR growth, self-efficacy and connection between engineering and the social dimension) showed that the CEL had a positive impact on SR development.

\subsection{Future Work}

Larger studies are planned to work with these tools to measure how different types of CEL develop different trends in social responsibility (SR) development. By finetuning the array of tools used in this study, we aim to discover more about the relationship between different types of Community Engaged Learning (CEL) activities and impact on SR.

Since the Homes of Hope trip is expected to be an ongoing regular trip, repeating the same measurements of social responsibility measurement would be valuable in understanding the degree of impact from other factors aside from the CEL activity type. While maintaining a consistent type of CEL, we would be able to verify the degree that other factors (such as initial SR profile, demographic features, personal motivators) impact the SR development patterns.

There is potential for the SR landscape and individual SR profile to be used as a guide to informed curriculum modifications. Additionally, there is also potential for EPICS-style service learning platforms to use the individual SR profiles to 'recommend' different types of service or community engaged learning experiences based on the different SR realms or constructs that need development.

\section{Acknowledgements}

The authors wish to thank the Suncor Energy Foundation and the Schulich School of Engineering for their generous support of this research. Additionally we wish to thank Boardwalk Real Estate who has been supporting the collaboration between our school and the Homes of Hope trip for many years. Finally, we would like to thank the students of the 2015 Homes of Hope trip participants for their commitment to improving engineering education, and especially for their thoughtful responses to the survey questions.

\section{References}

[1] A. Chan and J. Fishbein, "A global engineer for the global community," J. Policy Engagem., vol. 1, no. 2, pp. 4-9, 2009.

[2] "NAE Grand Challenges for Engineering," Committee of the National Academy of Engineering, 2008. [Online]. Available: $\mathrm{http}: / / \mathrm{www}$.engineeringchallenges.org/cms/challenges.a spx. [Accessed: 15-Feb-2015].

[3] CEAB, "2014 Accreditation Criteria and Procedures," Engineers Canada, 2014. [Online]. Available: http://www.engineerscanada.ca/sites/default/files/2014_ accreditation_criteria_and_procedures_v06.pdf. [Accessed: 30 -Apr-2015].

[4] ABET, "2014-2015 Policies and Procedures Manual," Engineering Accreditation Commission, 2015. [Online]. Available: http://www.abet.org/accreditationcriteria-policies-documents/. [Accessed: 30-Apr-2015].

[5] N. E. Canney, “AC 2012-3889: A MODEL FOR THE DEVELOPMENT OF PERSONAL A Model for the Development of Personal and Professional Social Responsibility for Engineers," 2012.

[6] L. J. Shuman, M. Besterfield-Sacre, and J. McGourty, "The ABET 'Professional Skills' - Can They Be Taught? Can They Be Assessed?," J. Eng. Educ., vol. 94, no. January, pp. 41-55, 2005.

[7] J. Duffy, L. Barrington, C. West, M. Heredia, and C. Barry, "Service-learning integrated throughout a college of engineering (SLICE)," Adv. Eng. Educ., vol. 2, pp. 1-23, 2010.

[8] A. W. Astin, L. J. Vogelgesang, E. K. Ikeda, and J. a Yee, "How Service Learning Affects Students," 2000.

[9] C. B. Zoltowski and W. Lafayette, "Immersive Community Engagement Experience," in ASEE Annual Conference and Exposition, Conference Proceedings, 2014.

[10] E. Science, "Spectra of Learning Through Service Programs Spectra of Learning Through Service Programs," 2013.

[11] L. Vanasupa and L. Schlemer, "Relational versus transactional community engagement: An experience 
of the benefits and costs," Am. Soc. Eng. Educ., no. 1985, 2014.

[12] A. Bielefeldt and N. E. Canney, "Social Responsibility Attitudes of First Year Engineering Students and the Impact of Courses Social Responsibility Attitudes of First Year Engineering Students and the Impact of Courses," ASEE Annu. Conf. Expo. Conf. Proc., 2014.

[13] (YWAM) and Youth with a Mission, "Homes of Hope Trip," 2015. [Online]. Available:

http://www.ywamsandiegobaja.org/homesofhope/. [Accessed: 29-Apr-2015].

[14] N. E. Canney, “Assessing Engineering Students' Understanding of Personal and Professional Social Responsibiliy NATHAN E . CANNEY, P . E . M . S ., Stanford University, 2010 A thesis submitted to the Faculty of the Graduate School of the University of Colorado in," University of Colerado, 2013.

[15] R. W. Brennan and R. J. Hugo, "Reinforcing Skills and Building Student Confidence through a Multicultural Project-based Learning Experience The PjBL Course," Cdio 2012 Qut, 2012.

[16] "Full-Time Enrollment by Year of Program, Gender \& Degree Sought," University of Calgary Institutional Analysis - Fact Book, 2014. .

\section{APPENDIX A: Survey Design Samples}

\section{A.1 Excerpt from EPRA Assessment Tool}

This survey tool sample was taken directly from Canney's PhD thesis [14].

\begin{tabular}{c|c|c|c|c}
1 & 2 & 3 & 4 & 5 \\
\hline $\begin{array}{c}\text { Strongly } \\
\text { Disagree }\end{array}$ & Disagree & $\begin{array}{c}\text { Slightly } \\
\text { Disagree }\end{array}$ & Neutral & $\begin{array}{c}\text { Slightly } \\
\text { Agree }\end{array}$
\end{tabular}

\begin{tabular}{|c|c|c|}
\hline $\begin{array}{r}\text { Engineers have contributed greatly to fixing problems in the } \\
\text { world }\end{array}$ & 1 & 2 \\
\hline $\begin{array}{l}\text { I would not change an engineering design because it } \\
\text { conflicted with community feedback }\end{array}$ & 1 & 2 \\
\hline $\begin{array}{r}\text { Volunteer experience(s) have changed the way I think about } \\
\text { spending money }\end{array}$ & 1 & 2 \\
\hline $\begin{array}{r}\text { It is important to me personally to have a career that } \\
\text { Involves helping people }\end{array}$ & 1 & 2 \\
\hline $\begin{array}{r}\text { Engineering skills are not useful in making the community a } \\
\text { better place }\end{array}$ & 1 & 2 \\
\hline $\begin{array}{l}\text { It is important for engineers to consider the potential } \\
\text { broader impacts of technical solutions to problems }\end{array}$ & 1 & 2 \\
\hline $\begin{array}{r}\text { Community service work should not be an expected part of } \\
\text { the engineering }\end{array}$ & 1 & 2 \\
\hline $\begin{array}{r}\text { I would be willing to have a career that earns less money if I } \\
\text { were serving society }\end{array}$ & 1 & 2 \\
\hline
\end{tabular}

\section{A.2 Excerpt from Self-Efficacy Assessment Tool}

This survey tool sample was taken directly from Hugo and Brennan's work [15]. Shown here are the questions relating to self-efficacy measures of the two graduate attributes relevant to social responsibility that we measured. The first three questions measure "Impact of Engineering on Society and the Environment" and the second set of three questions measure "Professionalism".

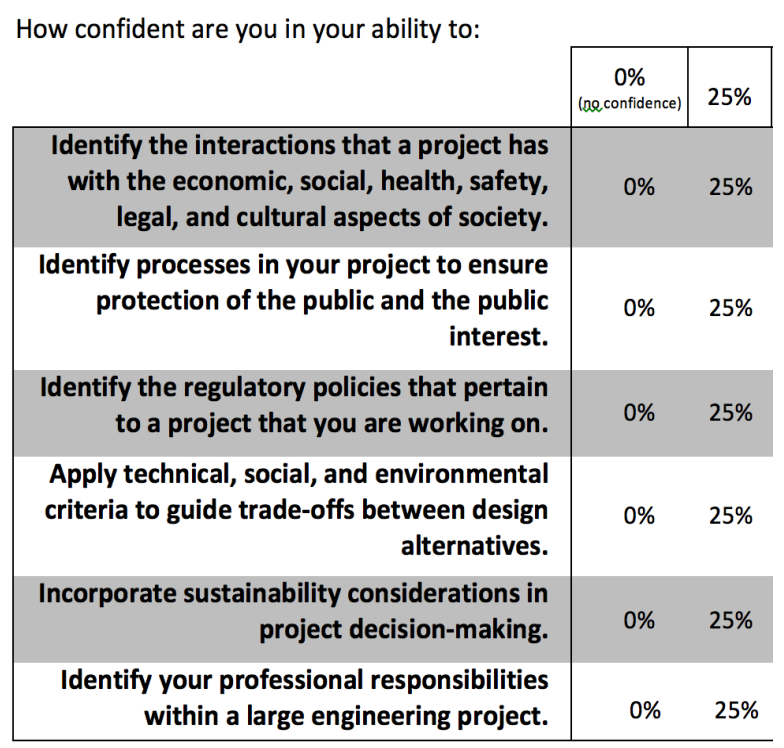

\section{A.2 Sample Qualitative Answers and Coding}

These answers are excerpts of the students responses and how coding was done between qualitative responses both pre and post survey. These are responses to the question was "How do you think having participated on this trip will benefit you in the future? (Personally, Professionally, Academically)'.

\begin{tabular}{|c|c|c|}
\hline$\frac{\text { PSRDM Construct and }}{\text { Description [14] }}$ & $\frac{\text { Example Survey }}{\text { Answers }}$ & $\underline{\text { Keywords/Phrases }}$ \\
\hline $\begin{array}{l}\text { 1. Awareness } \\
\text { (Personal) } \\
\text { An awareness that } \\
\text { others are in need. }\end{array}$ & $\begin{array}{l}\text { "expose me to people } \\
\text { of different } \\
\text { circumstances and } \\
\text { culture, develop } \\
\text { interpersonal skills" } \\
\text { "see lifestyles" of } \\
\text { others" } \\
\text { have a wholesome } \\
\text { view of the world" } \\
\text { see the world in a new } \\
\text { perspective, be } \\
\text { thankful } \\
\text { gain a sense of } \\
\text { different qualities of }\end{array}$ & $\begin{array}{l}\text { Exposure } \\
\text { Awareness } \\
\text { View } \\
\text { Perspective } \\
\text { Insight } \\
\text { Circumstances } \\
\text { Lifestyles } \\
\text { Cultures/world } \\
\\
\text { Eye-Opening } \\
\text { Humbling } \\
\text { Appreciation }\end{array}$ \\
\hline
\end{tabular}




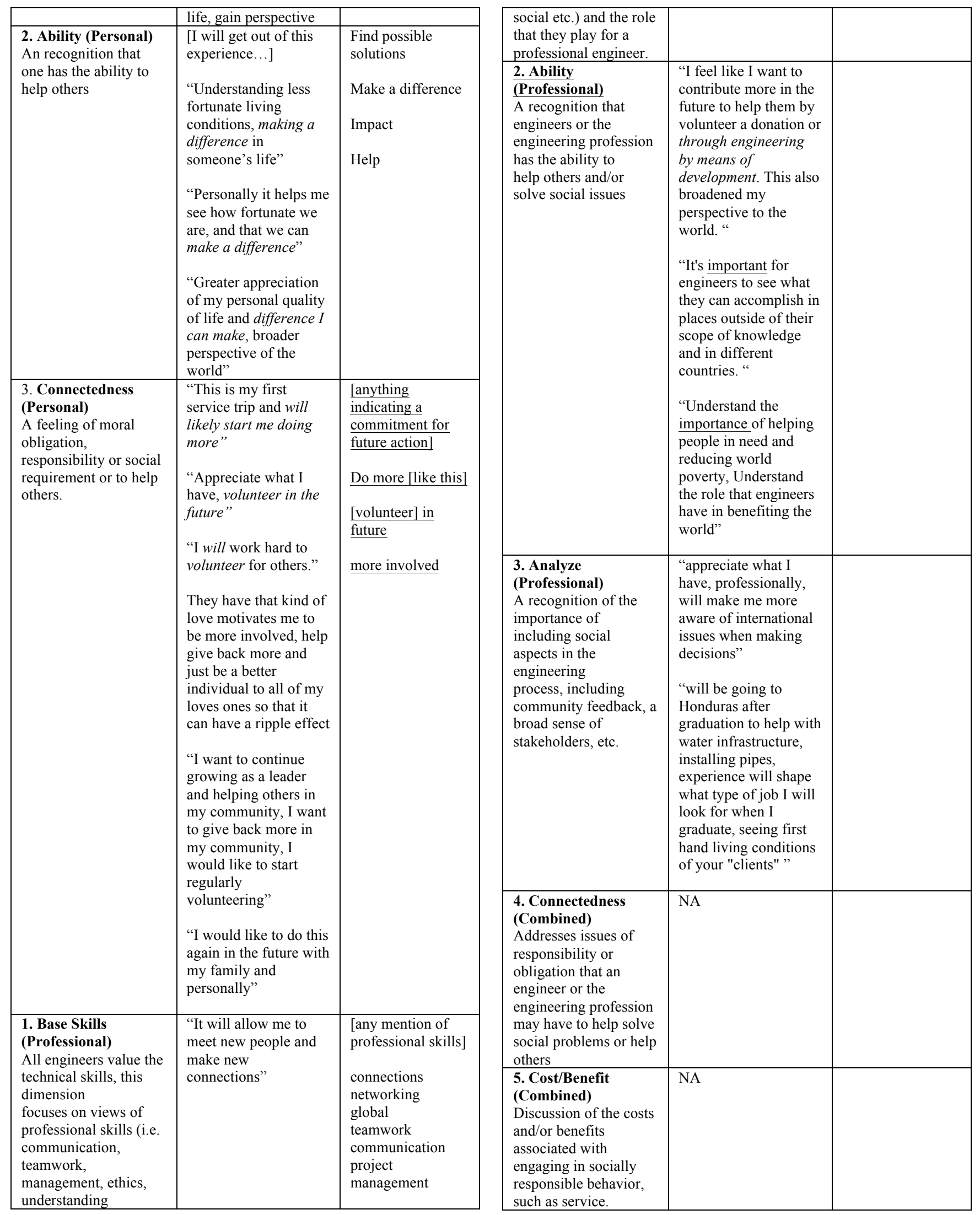

